\title{
The cation-transporting P-type ATPase Cta4 is required for assembly of the forespore membrane in fission yeast
}

\author{
Shu-hei Yoshida ${ }^{\dagger}$, Taro Nakamura and Chikashi Shimoda* \\ Department of Biology, Graduate School of Science, Osaka City University, \\ Sugimoto, Sumiyoshi-ku, Osaka 558-8585, Japan
}

(Received 12 September 2005, accepted 23 October 2005)

\begin{abstract}
A novel sporulation-deficient mutant, sev4-L5, was isolated in a genetic screen of a collection of temperature-sensitive mutants of Schizosaccharomyces pombe. The wild-type sev4 gene was identified as $c t a 4^{+}$, which encodes a putative cationtransporting P-type ATPase. The sev4-L5 allele harbored a single missense mutation that caused replacement of Gly615 with a glutamate at the putative ATP-binding site. Similar to cta4-null mutants, sev4-L5 exhibited defects in growth at high and low temperatures, and sensitivity to high and extremely low concentrations of $\mathrm{Ca}^{2+}$. The $c t a 4^{+}$mRNA level was considerably enhanced during meiosis. When sev4-L5 cells were incubated in sporulation medium at the permissive temperature, meiotic nuclear divisions proceeded with normal kinetics, but spores were not formed. Structural alteration of the spindle pole body, which is prerequisite to construction of the forespore membrane in wild type, was incomplete. Consequently, formation of the forespore membrane was severely impaired. These observations show that perturbation of $\mathrm{Ca}^{2+}$ homeostasis by mutation of cta4/sev4 blocks sporulation mainly by interfering with forespore membrane assembly.
\end{abstract}

Key words: fission yeast, forespore membrane, meiosis, P-type ATPase, calcium homeostasis

\section{INTRODUCTION}

Sporulation in yeasts provides a model for gametogenesis in higher eukaryotes. An important step leading to ascospore formation is de novo assembly of the plasma membrane of newborn spores (Neiman, 1998; Shimoda, 2004). The spore plasma membrane is formed in the cytoplasm of zygotes as a double-layered intracellular membrane, termed the forespore membrane (FSM) in the fission yeast Schizosaccharomyces pombe (Yoo et al., 1973; Hirata and Tanaka, 1982; Tanaka and Hirata, 1982). The nascent FSM extends by fusing with vesicles derived from the ER/Golgi and encapsulates each of the meiotic nuclei (Hirata and Tanaka, 1982; Tanaka and Hirata, 1982; Nakamura et al., 2001). The inner membrane of the FSM becomes the plasma membrane of the spores. Formation of the FSM initiates during meiosis II near the spindle pole body (SPB), a microtubule-organizing center in yeast that is equivalent to the centrosome.

Edited by Hideo Shinagawa

* Corresponding author. E-mail: shimoda@sci.osaka-cu.ac.jp

${ }^{\dagger}$ Present address: Department of Molecular Genetics, Graduate School of Medicine, Osaka City University, Asahi-cho, Abenoku, Osaka 545-8585, Japan
Before formation of the FSM, the SPB undergoes a morphological change from a dot to a crescent shape (Hagan and Yanagida, 1995), and this modification seems to be essential for FSM formation (Hirata and Shimoda, 1994; Ikemoto et al., 2000). These facts imply that the SPB plays an important role in membrane assembly, but the mechanistic details are still elusive.

Genetic and molecular analyses of many sporulationspecific mutants in $S$. pombe have dissected the molecular events that occur during meiosis and sporulation (Bresch et al., 1968; Kishida and Shimoda, 1986; Shimoda and Nakamura, 2004). In addition to specific genes termed spo, we have also screened for asporogenous mutants out of a collection of temperature-sensitive mutants (Yoshida et al., 2003). These mutants, referred to as "sev" (for sporulation genes essential for vegetative growth), have defined five genes. sev $1^{+}$is identical to $c d t 2^{+}$, which is responsible for mitotic and premeiotic DNA replication (Yoshida et al., 2003). In this article, we report the analysis of $s e v 4^{+}$, which encodes $\mathrm{Cta} 4$, a putative $\mathrm{Ca}^{2+}$ ATPase.

$\mathrm{Ca}^{2+}$ is an essential component of cellular signal transduction. The intracellular concentration of $\mathrm{Ca}^{2+}$ is strictly regulated, and perturbation of $\mathrm{Ca}^{2+}$ homeostasis 
causes various disorders in cell growth and function. Analysis of the cta4-null mutant previously revealed that $\mathrm{Ca}^{2+}$ homeostasis is crucial for growth and cell polarity (Okorokova-Facanha et al., 2002). Influx of $\mathrm{Ca}^{2+}$ into cells is triggered during conjugation in budding yeast (Iida et. al., 1994). The $\mathrm{Ca}^{2+}$-binding protein calmodulin and its downstream protein phosphatase calcineurin are also involved in cell polarity and mating in yeast (Liu et al., 1990; Cyert et al., 1991; Ohya and Botstein, 1994; Yoshida et. al., 1994). To data, however, little information is available on the requirement of intracellular $\mathrm{Ca}^{2+}$ homeostasis for meiosis and sporulation. Here we report that mutation of sev4/cta4 causes severe disorders in sporulation.

\section{MATERIALS AND METHODS}

Yeast strains, media and genetic techniques. The $S$. pombe strains used in this study are listed in Table 1. Complete medium $\mathrm{YE}$ and minimal medium $\mathrm{EMM} 2+\mathrm{N}$ were used for growth. Sporulation media MEA, SSA and EMM2-N were used for mating and sporulation (Egel and Egel-Mitani, 1974; Gutz et al., 1974; Moreno et al., 1991). The original sev4-L5 mutant was derived from C982-16C. The method for synchronous meiosis has been described in our previous report (Yoshida et al., 2003).

To construct a cta4-null allele, a major part of the ORF (amino acids 64 to 993) was replaced by a $u r a 4^{+}$cassette (Grimm et. al., 1988). The DNA fragment containing the cta4:: $\mathrm{ura}^{+}$allele was introduced into the diploid strain SYD1 and uracil prototrophs were isolated. Correct integration of the disrupted allele at the $s e v 4^{+}$locus was verified by Southern blot analysis, as described previously (Yoshida et al., 2003).

Construction of cta4-HA. Triple hemagglutinin (HA) epitope-tagged $c t a 4^{+}$was constructed as follows. The cta $4^{+}$coding region was amplified by PCR using primers CCCGTCGAC (SalI)GGGGAGTAAGGCTTTA and GGGGCGGCCGC(NotI)AATTACGAAGAACAAT. The amplified DNA fragment was digested with SalI and NotI and then inserted into pTN218 containing the HA (3x) and the $n m t 1$ terminator (Nakamura et. al., 2002) to yield a cta4$H A$ integration plasmid pSY05004. pSY05004 was linearized at a single $S t u \mathrm{I}$ site in the Cta4-coding region and transformed into TN29 to create SY70, in which a single copy of the Cta4-HA allele with a cta4 native promoter was integrated at the chromosomal cta4 locus.

Northern blot analysis. Total RNA was prepared from the pat1-114 mutant strain (JZ670) at hourly intervals after induction of meiosis (Jensen et al. 1983). RNA was fractionated on a $1.0 \%$ agarose gel containing $3.7 \%$ formaldehyde (Thomas, 1980), blotted and then probed with the cta $^{+}$-specific probe. The probe DNA was labeled with $\left[{ }^{32} \mathrm{P}\right] \mathrm{dCTP}$ by the random primer method (Feinberg et al., 1983).

Nucleotide sequence analysis of the sev4-L5 allele. The complete sev4-L5 ORF was amplified by PCR by using genomic DNA prepared from SY13 as a template. Amplified DNA fragments were directly sequenced with an ABI-PRISM 310 autosequencer (Applied Biosystems, CA, USA). The nucleotide sequence of the sev4-L5 allele was compared with the published

Table 1. Strain list

\begin{tabular}{llll}
\hline \hline Strains & Genotype & Reference/Source \\
\hline C982-16C & $\mathrm{h}^{90}$ & ura4-D18 & Yoshida et al. (2003) / YGRC* \\
C996-11D & $\mathrm{h}^{90}$ & leu1-32 & Yoshida et al. (2003) /YGRC* \\
FS26 & $\mathrm{h}^{90}$ & & YGRC* \\
SY13 & $\mathrm{h}^{90}$ & sev4-L5 & This study \\
SY15 & $\mathrm{h}^{90}$ & sev4-L5 leu1-32 & This study \\
SY34 & $\mathrm{h}^{90}$ & cta4::Ura4 ${ }^{+}$ura4-D18 & This study \\
SY60 & $\mathrm{h}^{90}$ & sev4-L5 leu1 << GFP-psy1 leu1-32 & This study \\
SY70 & $\mathrm{h}^{90}$ & cta4-HA<<LEU2 ura4-D18 leu1-32 & This study \\
TN29 & $\mathrm{h}^{90}$ & ura4-D18 leu1-32 & Ikemoto et al. (2000)/ YGRC* \\
YN68 & $\mathrm{h}^{90}$ & leu1 << GFP-psy1 leu1-32 & Nakase et al. (2004) / YGRC* \\
JZ670 & $\mathrm{h}^{-} / \mathrm{h}^{-}$ & pat1-114 / pat1-114 ade6-M210 / ade6-M216 leu1-32 / leu1-32 & Iino et al. (1995) / YGRC* \\
SYD1 & $\mathrm{h}^{90} / \mathrm{h}^{90}$ & ura4-D18 / ura4-D18 leu1-32 / leu1-32 & This study \\
SYD2 & $\mathrm{h}^{+} / \mathrm{h}^{-}$ & ade6-M210 / ade6-M216 & This study \\
SYD3 & $\mathrm{h}^{+} / \mathrm{h}^{-}$ & sev4-L5 / sev4-L5 ade6-M210 / ade6-M216 & This study
\end{tabular}

*YGRC, Yeast Genetic Resource Center Japan (http://bio3.tokyo.jst.go.jp/jst/). The strains constructed in this study will be deposited in the YGRC. 
sequence of $\operatorname{cta4}^{+}$(Okorokova-Facanha et al., 2002).

Immunofluorescence microscopy. For cell fixation, we followed the method of Hagan and Hyams (1988) using glutaraldehyde and paraformaldehyde. Cta4-HA was visualized by indirect immunofluorescence microscopy using rat anti-HA antibody 3F10 (Boehringer Mannheim, Mannheim, Germany) and Alexa 546-conjugated goat anti-rat IgG (Molecular Probes, Eugene, USA). The SPB was visualized by indirect immunofluorescence microscopy using rabbit anti-Sad1 antibody and Alexa 546-conjugated goat anti-rabbit IgG (Molecular Probes). For microtubule staining, TAT- 1 anti- $\alpha$-tubulin antibody (Woods et al., 1989) and Cy3-conjugated secondary antibody (Sigma Chemical Co., St. Luis, USA) were used. To visualize the nuclear chromatin region, cells were stained with 4',6-diamidino-2-phenylindole (DAPI) at $1 \mu \mathrm{g} / \mathrm{ml}$. Stained cells were observed under a fluorescence microscope (model BX51; Olympus, Tokyo) equipped with a charge-coupled device (CCD) camera (Cool-SNAP; Roper Scientific, San Diego, USA).

\section{RESULTS AND DISCUSSION}

Isolation of a sporulation-deficient sev4-L5 mutant. In a genetic screen for sporulation-deficient mutants present in a collection of temperature-sensitive mutants of $S$. pombe, we previously isolated sev mutants and identified five sev loci (Yoshida et al. 2003). Genetic analysis of the sev4-L5 mutant indicated that its mutant phenotype was due to a single recessive mutation. sev4-L5 cells were unable to form colonies either at $37^{\circ} \mathrm{C}$ or at $19^{\circ} \mathrm{C}$ on YEA plates (Fig. 1A). The mutant cells grew very poorly in EMM2+N supplemented with $0.5 \mathrm{M} \mathrm{CaCl}_{2}$ or in $\mathrm{Ca}^{2+}$-free EMM2+N containing $10 \mathrm{mM}$ EGTA (data not shown). The growth in the latter medium was recovered by adding $20 \mathrm{mM} \mathrm{CaCl}{ }_{2}$ (data not shown). A homothallic haploid strain carrying sev4-L5 was incubated in nitrogen-limited medium MEA at the permissive temperature $\left(28^{\circ} \mathrm{C}\right)$ for two days. Cells conjugated to form zygotes at a lower efficiency than did wild-type control cells, and notably produced no asci (Table 2 and Fig. 1B).

Identification of the sev4 ${ }^{+}$gene. An S. pombe genomic library (pTN-L1) (Nakamura et al., 2001) was introduced into the sev4-L5 mutant. Plasmid DNA was prepared from a few $\mathrm{Spo}^{+}$transformants, and both termini of the inserted fragment were sequenced to identify the cloned gene. Comparison with the $S$. pombe genome sequence database (http://www.sanger.ac.uk/Projects/ S_pombe/) showed that the insert contained two ORFs. Subcloning experiments determined the ORF (SPACUNK4.07c, also known as $c t a 4^{+}$) responsible for the complementation activity, and integration mapping
A
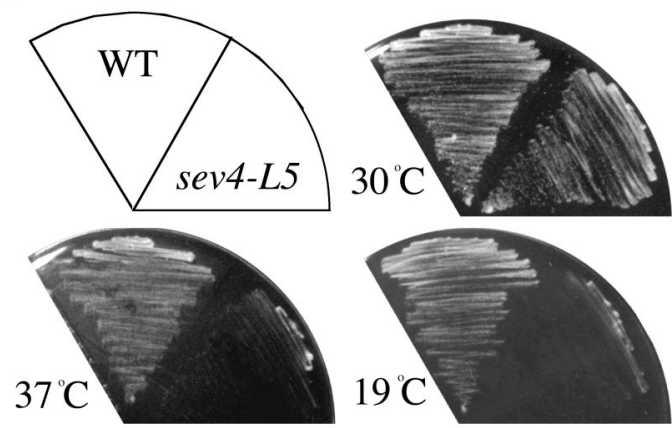

B
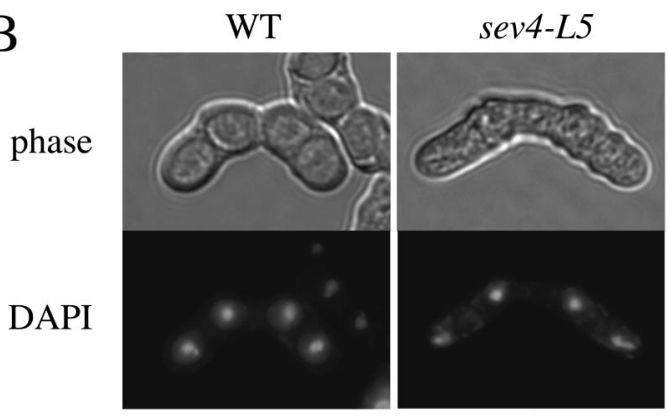

Fig. 1. Phenotype of the sev4 mutant. (A) Colony formation at different incubation temperatures. Wild-type (C996-11D) and sev4-L5 (SY15) cells were incubated on YE plates at $28^{\circ} \mathrm{C}$ for 2 days, at $37^{\circ} \mathrm{C}$ for 2 days, or at $19^{\circ} \mathrm{C}$ for 3 days. (B) Mating and sporulation ability of the sev4-L5 mutant. Wild-type (C99611D) and sev4-L5 (SY15) cells were incubated on MEA plates at $28^{\circ} \mathrm{C}$ for 2 days. After fixation with $70 \%$ ethanol, cells were stained with DAPI. Bar, $10 \mu \mathrm{m}$.

Table 2. Efficiency of conjugation and sporulation in sev4 mutant

\begin{tabular}{llc}
\hline \hline & Conjugation (\%) & Sporulation (\%) \\
\hline WT & 64.1 & 86.1 \\
sev4-L5 & 24.3 & 0 \\
$\Delta$ cta4 & 30.8 & 0 \\
\hline
\end{tabular}

Wild-type (FS26), sev4-L5 (SY13), and cta4A (SY34) cells were cultured on MEA plates at $28^{\circ} \mathrm{C}$ for 2 days. Over 300 cells were counted for each strain. Efficiencies of conjugation and sporulation were calculated by the following equations: Conjugation $(\%)=(2 \times[$ Zygotes $]+2 \times[$ Asci] $) \times 100 /(2 \times$ [Zygotes $]+2 \times[$ Asci $]+[$ Vegetative cells $])$ Sporulation $(\%)=[$ Asci $] \times 100 /([$ Asci $]+[$ Zygotes $])$

verified that the cloned gene was indeed the defined $\operatorname{sev} 4^{+} /$cta $^{+}$gene.

cta $4^{+}$encodes a cation-transporting P-type ATPase that specifically localizes to the endoplasmic reticulum (ER) (Okorokova-Facanha et al., 2002). The cta4-null mutation markedly increases the cellular $\mathrm{Ca}^{2+}$ concentration, indicating that $\mathrm{Cta} 4$ is responsible for $\mathrm{Ca}^{2+}$ homeostasis in S. pombe (Okorokova-Facanha et al., 2002). Sequencing of the sev4-L5 allele revealed that it contained a single mutation of $\mathrm{G}$ to $\mathrm{A}$ at nucleotide 1844. This mutation 
predicts the substitution of Gly615, which is located in the conserved ATP-binding site, with a glutamate residue. As the phenotype of the sev4-L5 mutant closely resembled that of the cta4-null mutant, the ATP-binding activity must be essential for the function of Cta4.

Expression and localization of Cta4. To examine the expression of $\mathrm{cta4}^{+}$, we estimated the mRNA abundance by Northern blot analysis. Synchronous meiosis was conducted in the pat1-114 mutant, JZ670 (Iino and Yamamoto, 1995). The cta4 hybridization signal was detected in the cell sample at $0 \mathrm{hr}$ (vegetative cells) and intensified at around 6-7 hr after the induction of meiosis, corresponding to meiosis I (Fig. 2). cta4 mRNA was also present in exponentially growing cultures (data not shown). This result is consistent with DNA microarray data showing that transcription of $\mathrm{cta4}^{+}$is transiently upregulated during meiosis (Mata et al., 2002). We thus conclude that cta $4^{+}$transcription is constitutive in vegetative cells and is upregulated significantly during meiosis.

\section{A}

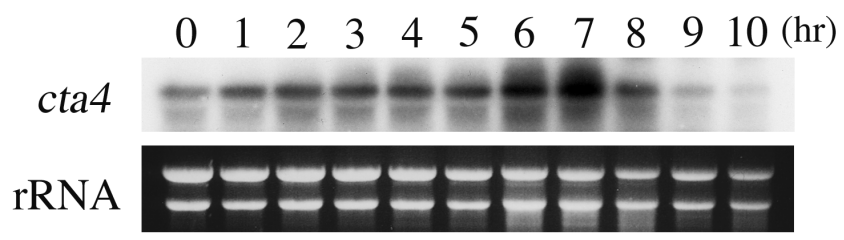

B

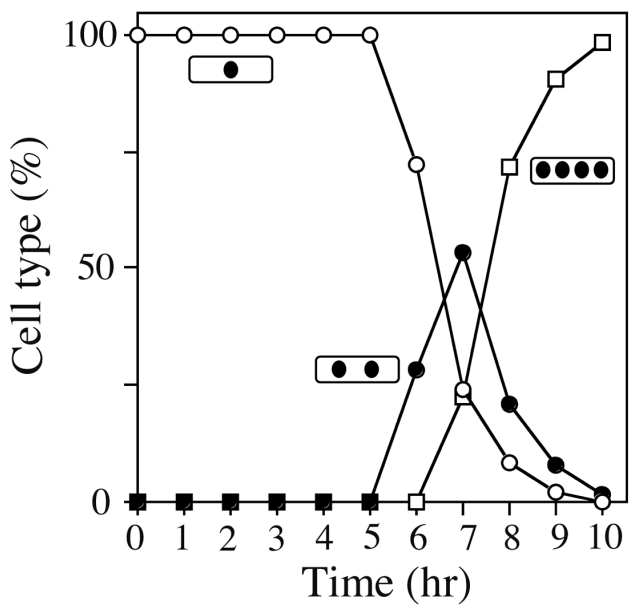

Fig. 2. Northern blot analysis of $\mathrm{cta4}^{+}$mRNA. The pat1-114 homozygous diploid strain (JZ670) was incubated in EMM2-N for $15 \mathrm{hr}$ at $25^{\circ} \mathrm{C}$ and then shifted to $34^{\circ} \mathrm{C}$ to induce synchronous meiosis. At hourly intervals, aliquots were removed for RNA preparation. (A) Autoradiogram of RNA blots with a cta4-specific probe. Ethidium bromide staining of ribosomal RNAs is presented as a loading control (bottom). (B) To monitor the meiotic nuclear divisions, the number of nuclei per cell was determined after DAPI staining.
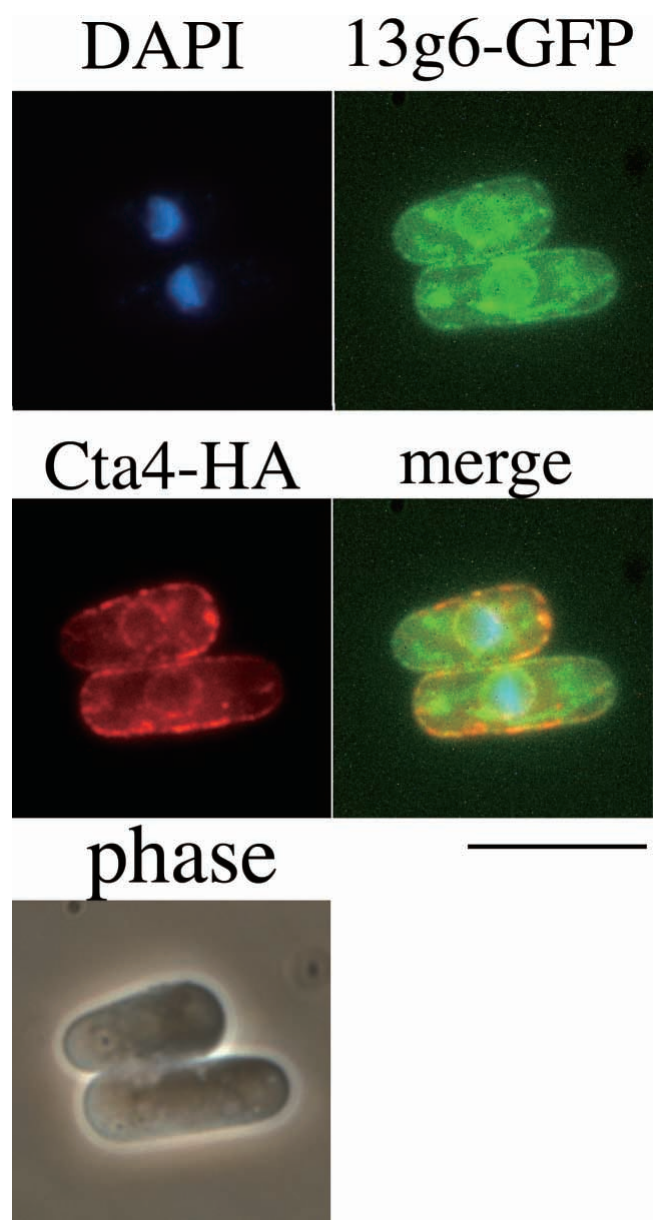

Fig. 3. Localization of Cta4-HA to the ER. Vegetative cells of an integrant strain SY70 was fixed, treated with anti-HA antibody (3F10), and stained with Alexa 594-conjugated anti-rat IgG antibody and DAPI. A phase-contrast image is also presented. Bar $10 \mu \mathrm{m}$.

A GFP-Cta4 fusion protein has been reported to localize to the ER (Okorokova-Facanha et al., 2002). To verify this result, we constructed a strain carrying a single copy of the cta4-HA allele that was expressed under the control of a cta 4 native promoter. The integrant strain was then transformed with pREP82(13g6-GFP), which was a $\mathrm{ura4}^{+}$ -carrying version of pREP81(13g6-GFP) (Nakamura-Kubo et al. 2003), to visualize an ER marker protein $13 g 6$ (Brazer et. al., 2000). Both signals were colocalized to the nuclear periphery and beneath the plasma membrane; this localization is typical of proteins associated with the ER (Fig. 3). These findings support the idea that $\mathrm{Cta} 4$ is a cation-transporting ATPase localized to the ER.

sev4-L5 was defective in development of the FSM. The cta4-null mutant showed elevated levels of intracellular $\mathrm{Ca}^{2+}$ concentration (Okorokova-Facanha et al., 2002). We thus examined whether externally added $\mathrm{CaCl}_{2}$ influenced conjugation and sporulation in wild-type 
cells. Homothallic wild-type strain (FS26) was cultured in nitrogen-free liquid medium, $\mathrm{EMM}^{2}-\mathrm{N}$, containing different concentrations of $\mathrm{CaCl}_{2}$. Cells were cultured with shaking at $28^{\circ} \mathrm{C}$ for 2 days. $\mathrm{CaCl}_{2}$ at concentrations higher than $0.5 \mathrm{M}$ markedly inhibited conjugation. At lower concentrations, $0.1-0.4 \mathrm{M}, \mathrm{CaCl}_{2}$ moderately inhibited conjugation, but did not significantly affect sporulation (data not shown).

As external $\mathrm{Ca}^{2+}$ addition preferentially blocked the zygote formation, we studied the requirement of $\mathrm{Ca}^{2+}$ homeostasis for the later stages of sexual development, meiosis and sporulation, with the sev4-L5 mutant. First, the kinetics of meiosis in diploid strains was monitored by DAPI staining of the nuclear chromatin region. As shown in Fig. 4, timing of the meiotic nuclear divisions in the sev4-L5 homozygous diploid was similar to that in the wild-type strain with a slight increase in the remaining mononucleate cells. Thus, it seems unlikely that the sporulation deficiency in sev4-L5 is due to a failure in the progression of meiosis.

Formation of the FSM, as visualized by GFP-Psy1, commences during meiosis II (Nakamura et al., 2001). Wildtype and sev4-L5 cells expressing GFP-Psy1 were cultured at $28^{\circ} \mathrm{C}$ on SSA sporulation medium. Fixed cells were immunostained with an antibody against $\alpha$-tubulin (TAT-1) (Woods et. al., 1989) or an anti-Sad1 antibody (Hagan and Yanagida, 1995) to monitor microtubules or the SPB, respectively. Progression of meiosis was also traced by staining cells with DAPI. Assembly of the FSM began at metaphase II near the spindle poles in both

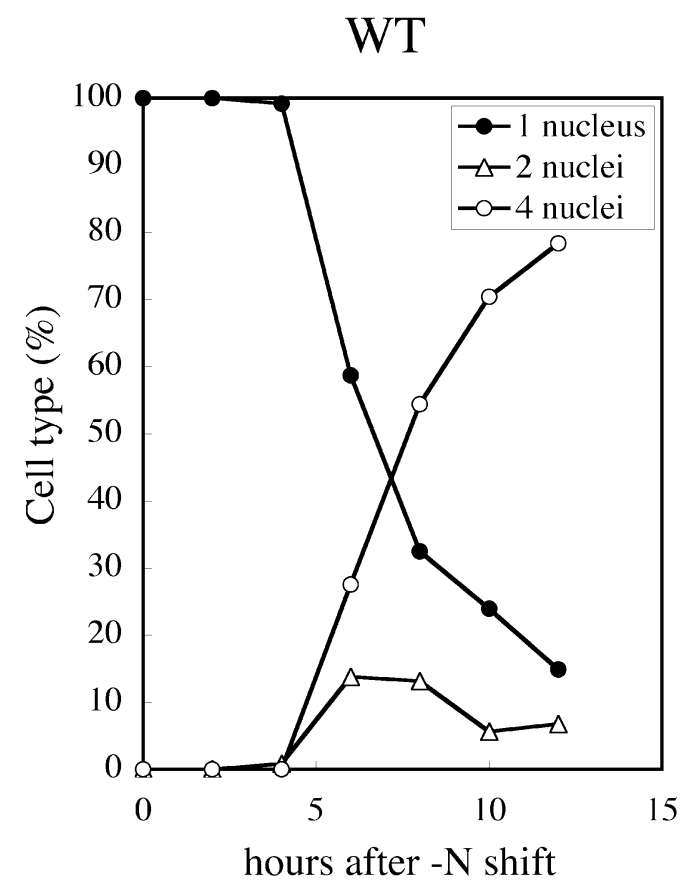

strains (Fig. 5). Cup-shaped structures typical of an early stage of FSM were observed in the sev4-L5 mutant (Fig. 5, metaphase II), but extension of the FSM appeared to be aberrant (Fig. 5, anaphase II). As a result, malformed and anucleated prespores were frequently produced. Finally, we analyzed quantitatively the terminal morphology of the FSM in post-meiotic, tetranucleate cells. In most wild-type cells, the FSM developed into closed membrane compartments termed prespores, each of which contained one haploid nucleus (Fig. 6A, Class I). By contrast, normal nucleated prespores were rarely found in sev4-L5; instead, this mutant exhibited abnormal morphology that could be classified into three main groups: zygotes that formed four prespores, but some of which were anucleated (Fig. 6A, Class II); zygotes that formed malformed and/or anucleated prespores (Fig. 6A, Class III); and zygotes that formed only amorphous aggregates of the FSM (Fig. 6A, Class IV). The distribution of these classes in wild-type and sev4-L5 zygotes is summarized in Fig. 6B. Normal zygotes containing four nucleated prespores were rarely found in sev4-L5.

Similar aberrant FSM morphology has been observed in several asporogenous mutants such as spo3, spo14 and spo20 (Nakase et. al., 2001; Nakamura et. al., 2001; Nakamura-Kubo et. al., 2003), in which the fusion of membrane vesicles is impaired. Cta4 might be required for the vesicle fusion process to extend the FSM. We also noted that the structural modification of the compact SPBs to a crescent shape occurred only incompletely (Fig. 5B). The $S$. pombe calmodulin homologue encoded by

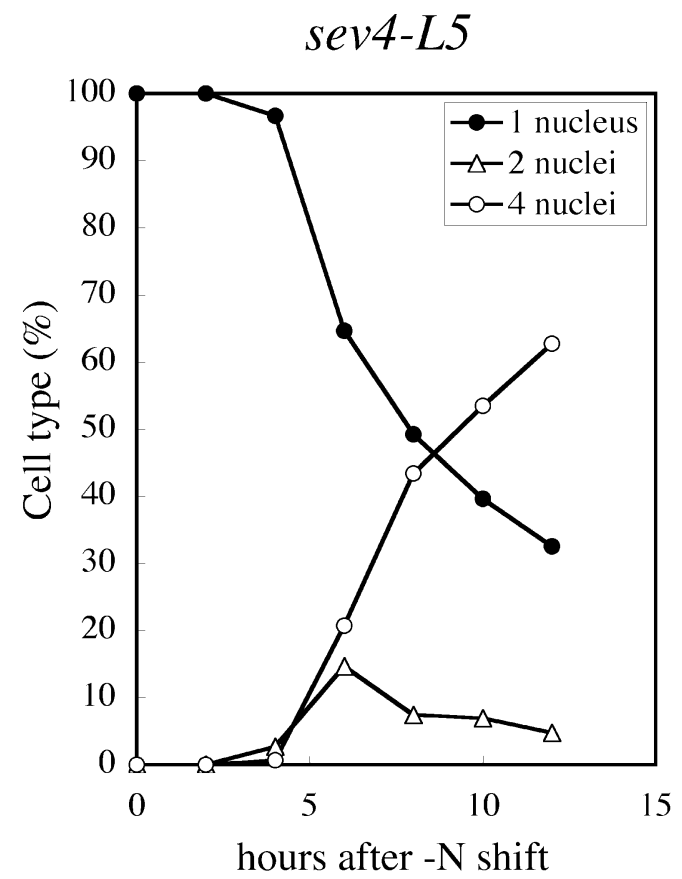

Fig. 4. Kinetics of meiotic nuclear divisions in the sev4-L5 mutant. Diploid strains homozygous for sev4 ${ }^{+}$(SYD2) and sev4L5 (SYD3) were incubated in $\mathrm{EMM}+\mathrm{N}$ for $16 \mathrm{hr}$ at $28^{\circ} \mathrm{C}$ and then shifted to $\mathrm{EMM}^{2}-\mathrm{N}$ to induce meiosis. To monitor the meiotic nuclear divisions, the number of nuclei per cell was determined after DAPI staining. 


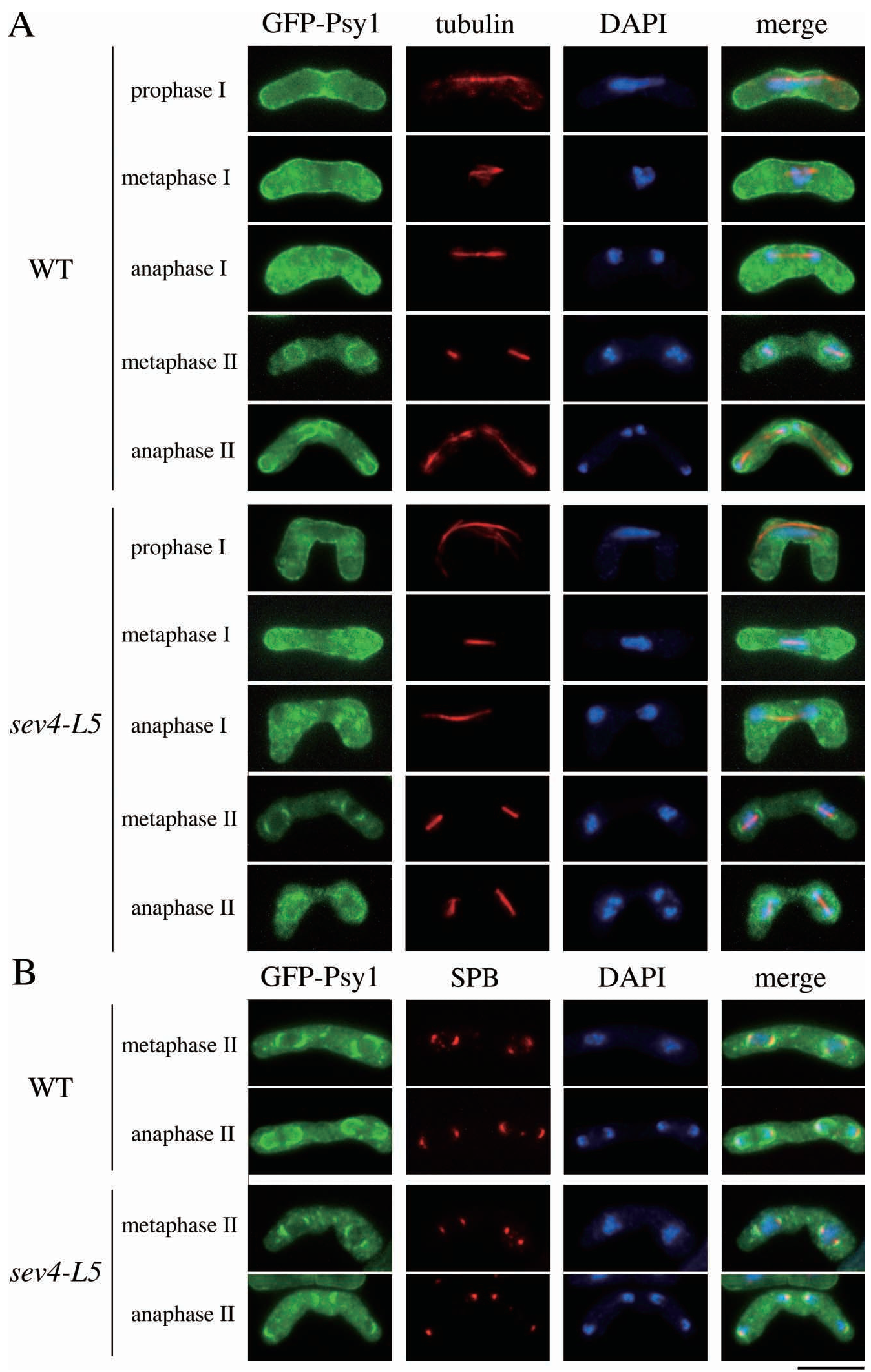

Fig. 5. Formation of the FSM in the sev4-L5 mutant. Homothallic strains of sev4 $4^{+}$(YN68) and sev4-L5 (SY60) were cultured on SSA plates for $24 \mathrm{hr}$ and then fixed. GFP-Psy1 signals were observed under a fluorescence microscope. Immunostaining of microtubules (A) and SPBs (B) was performed with anti- $\alpha$-tubulin and anti-Sad1 antibodies, respectively. Nuclear chromatin regions were stained with DAPI. Bar, $10 \mu \mathrm{m}$. 

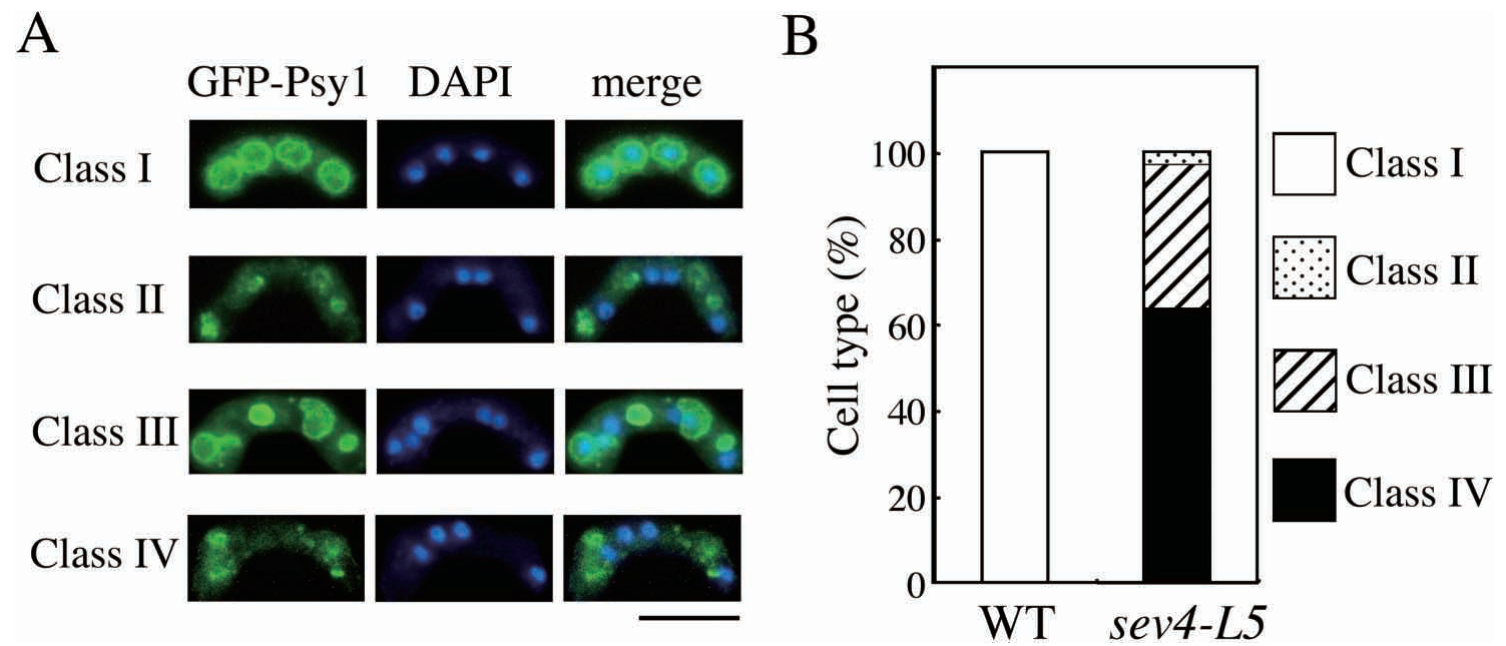

Fig. 6. Aberrant assembly of the FSM in the sev4-L5 mutant. Homothallic strains of sev4 ${ }^{+}$(YN68) and sev4-L5 (SY60) were cultured on SSA plates for 2 days at $28^{\circ} \mathrm{C}$. (A) Typical morphologies of the FSM and prespores visualized by GFP-Psy1. Cells were also stained with DAPI. Classification of zygotes: Class I, zygotes containing four normal nucleated prespores; Class II, zygotes containing anucleated prespores; Class III, zygotes containing malformed prespores; and Class IV, zygotes containing no prespores (only aggregates). (B) Relative frequency of cell types. Approximately 200 cells were scored for each sample.

cam $1^{+}$localizes to the SPBs (Moser et. al., 1997). A missense cam1-F116 mutant is also defective in sporulation (Takeda and Yamamoto, 1987) and shows marked defects in FSM formation (our unpublished data). This finding that the structural alteration of the SPB that normally takes place prior to formation of the FSM occurs only partially in the sev4-L5 mutant suggests the possibility that disturbances in $\mathrm{Ca}^{2+}$ homeostasis may inhibit the function of the SPB in constructing the FSM.

We thank O. Niwa of Kazusa DNA Research Institute for affinity-purified antibodies against Sad1, K. Gull of the University of Manchester for the anti- $\alpha$-tubulin antibody, TAT-1, and S. L. Forsburg of The Salk Institute for plasmids. We also thank M. Morita for her excellent technical assistance. The present study was supported by Grants-in-Aid for Scientific Research on Priority Area from the Japanese Ministry of Education, Culture, Sports, Science and Technology (MEXT) to C. S.(No.16013242) and to T. N. (No. 14037263).

\section{REFERENCES}

Brazer, S. C., Williams, H. P., Chappell, T. G., and Cande, W. Z. (2000) A fission yeast kinesin affects Golgi membrane recycling. Yeast 16, 149-166.

Bresch, C., Muller, G., and Egel, R. (1968) Genes involved in meiosis and sporulation of a yeast. Mol. Gen. Genet. 102, 301-306.

Cyert, M. S., Kunisawa, R., Kaim, D., and Thorner, J. (1991) Yeast has homologs (CNA1 and CNA2 gene products) of mammalian calcineurin, a calmodulin-regulated phosphoprotein phosphatase. Proc. Natl. Acad. Sci. USA. 88, 73767380 .

Egel, R., and Egel-Mitani, M. (1974) Premeiotic DNA synthesis in fission yeast. Exp. Cell Res. 88, 127-134.

Feinberg, A. P., and Vogelstein, B. (1983) A technique for radiolabeling DNA restriction endonuclease fragments to high specific activity. Anal. Biochem. 132, 6-13.
Grimm C., Kohli J., Murray J., and Maundrell K. (1988) Genetic engineering of Schizosaccharomyces pombe: a system for gene disruption and replacement using the ura4 gene as a selectable marker. Mol. Gen. Genet. 215, 81-86.

Gutz, H., Heslot, H., Leupold, U., and Loprieno, N. (1974) Schizosaccharomyces pombe, pp. 395-446 in Handbook of Genetics, edited by R. C. King. Plenum Press, New York.

Hagan, I., and Hyams, J. S. (1988) The use of cell division cycle mutants to investigate the control of microtubule distribution in the fission yeast Schizosaccharomyces pombe. J. Cell Sci. 89, 343-357.

Hagan, I., and Yanagida, M. (1995) The product of the spindle formation gene $\operatorname{sad} 1^{+}$associates with the fission yeast spindle pole body and is essential for viability. J. Cell Biol. 129, 1033-1047.

Hirata A., and Tanaka, K. (1992) Nuclear behavior during conjugation and meiosis in the fission yeast Schizosaccharomyces pombe. J. Gen. Appl. Microbiol. 28, 263-274.

Hirata, A., and Shimoda C. (1994) Structural modification of spindle pole bodies during meiosis II is essential for the normal formation of ascospores in Schizosaccharomyces pombe: ultrastructural analysis of spo mutants. Yeast 10, 173-183.

Iida, H., Nakamura, H., Ono, T., Okumura, M. S., and Anraku, Y. (1994) MID1, a novel Saccharomyces cerevisiae gene encoding a plasma membrane protein, is required for $\mathrm{Ca}^{2+}$ influx and mating. Mol. Cell Biol. 14, 8259-8271.

Iino, Y., Hirayama, Y., and Yamamoto, M. (1995) The role of $c d c 2$ and other genes in meiosis in Schizosaccharomyces pombe. Genetics 140, 1235-1245.

Ikemoto, S., Nakamura, T., Kubo, M., and Shimoda, C. (2000) S. pombe sporulation-specific coiled-coil protein Spo15p is localized to the spindle pole body and essential for its modification. J. Cell Sci. 113, 545-554.

Jensen, R., Sprague, Jr., G. F., and Herskowitz, I. (1983) Regulation of yeast mating-type locus. Proc. Natl. Acad. Sci. USA 80, 3035-3039.

Kishida, M., and Shimoda, C. (1986) Genetic mapping of eleven spo genes essential for ascospore formation in the fission yeast Schizosaccharomyces pombe. Curr. Genet. 10, 443- 
447.

Liu, Y. S., Yamashita, Y., Tsuchiya, E., and Miyakawa, T. (1990)Calmodulin-binding proteins of Saccharomyces cerevisiae. Biochem. Biophys. Res. Commun. 166, 681-686.

Mata, J., Lyne, R., Burns, G., and Bahler, J. (2002) The transcriptional program of meiosis and sporulation in fission yeast. Nature Genet. 32, 143-147.

Moreno, S., Klar, A., and Nurse, P. (1991) Molecular genetic analysis of fission yeast Schizosaccharomyces pombe. Methods Enzymol. 194, 795-823.

Moser, M. J., Flory, M. R., and Davis, T. N. (1997) Calmodulin localizes to the spindle pole body of Schizosaccharomyces pombe and performs an essential function in chromosome segregation. J. Cell Sci. 110, 1805-1812.

Nakamura, T., Nakamura-Kubo, M., Hirata, A., and Shimoda, C. (2001) The Schizosaccharomyces pombe spo $3^{+}$gene is required for assembly of the forespore membrane and genetically interacts with $p s y 1^{+}$-encoding syntaxin-like protein. Mol. Biol. Cell 12, 3955-3972.

Nakamura, T., Nakamura-Kubo, M., Nakamura, T., and Shimoda, C. (2002) Novel fission yeast Cdc7-Dbf4-like kinase complex required for the initiation and progression of meiotic second division. Mol. Cell Biol. 22, 309-320.

Nakamura-Kubo, M., Nakamura, T., Hirata, A., and Shimoda, C. (2003) The fission yeast spo $14^{+}$gene encoding a functional homologue of budding yeast Sec12 is required for the development of forespore membranes. Mol. Biol. Cell 14, 1109-1124.

Nakase, Y., Nakamura, T., Hirata, A., Routt, S. M., Skinner, H. B., Bankaitis, V. A., and Shimoda, C. (2001) The Schizosaccharomyces pombe spo $20^{+}$gene encoding a homologue of Saccharomyces cerevisiae Sec14 plays an important role in forespore membrane formation. Mol. Biol. Cell 12, 901917.

Nakase Y., Nakamura, T., Okazaki, K., Hirata, A., and Shimoda, C. (2004) The Sec14 family glycerophospholipid-transfer protein is required for structural integrity of the spindle pole body during meiosis in fission yeast. Genes Cells. Dec; 9(12), 1275-1286.

Neiman, A. M. (1998) Prospore membrane formation defines a developmentally regulated branch of the secretory pathway in yeast. J. Cell Biol. 140, 29-37.

Ohsumi, Y., and Anraku, Y. (1985) Specific induction of $\mathrm{Ca}^{2+}$ transport activity in MATa cells of Saccharomyces cerevisiae by a mating pheromone, alpha factor. J. Biol. Chem. 260, 10482-10486.

Ohya, Y., and Botstein, D. (1994) Diverse essential functions revealed by complementing yeast calmodulin mutants. Science 263, 963-966.

Okorokova-Facanha, A. L., Appelgren, H., Tabish, M., Okorokov, L., and Ekwall, K. (2002) The endoplasmic reticulum cation P-type ATPase Cta4p is required for control of cell shape and microtubule dynamics. J. Cell Biol. 157, 1029-1039.

Shimoda, C. (2004) Forespore membrane assembly in yeast: coordinating SPBs and membrane trafficking. J. Cell Sci. 117, 389-396.

Shimoda, C., and T. Nakamura (2004) Control of late meiosis and ascospore formation. In The Molecular Biology of Schizosaccharomyces pombe (ed. R. Egel), pp. 311-327. Berlin, Springer.

Takeda, T., and Yamamoto, M. (1987) Analysis and in vivo disruption of the gene coding for calmodulin in Schizosaccharomyces pombe. Proc. Natl. Acad. Sci. USA 84, 3580-3584.

Tanaka, K., and Hirata, A. (1982) Ascospore development in the fission yeasts Schizosaccharomyces pombe and $S$. japonicus. J. Cell Sci. 56, 263-279.

Thomas, P. S. (1980) Hybridization of denatured RNA and small DNA fragments transferred to nitrocellulose. Proc. Natl. Acad. Sci. USA 77, 5201-5205.

Woods, A., Sherwin, T., Sasse, R., MacRae, T. H., Baines, A. J., and Gull, K. (1989) Definition of individual components within the cytoskeleton of Trypanosoma brucei by a library of monoclonal antibodies. J. Cell Sci. 93, 491-500.

Yoo, B. Y., Calleja, G. B., and Johnson, B. F. (1973) Ultrastructural changes of the fission yeast (Schizosaccharomyces pombe) during ascospore formation. Arch. Mikrobiol. 91, $1-10$.

Yoshida, S., Al-Amodi, H., Nakamura, T., McInerny, C. J., and Shimoda, C. (2003) The Schizosaccharomyces pombe cdt2 ${ }^{+}$ gene, a target of G1-S phase-specific transcription factor complex DSC1, is required for mitotic and premeiotic DNA replication. Genetics 164, 881-893.

Yoshida T., Toda T., and Yanagida M. (1994) A calcineurin-like gene $p p b 1^{+}$in fission yeast: mutant defects in cytokinesis, cell polarity, mating and spindle pole body positioning. J. Cell Sci. 107, 1725-1735. 